\title{
HUBUNGAN KOMUNIKASI ANTAR PRIBADI PIMPINAN-BAWAHAN DAN KEPUASAN KERJA DENGAN KESETIAAN KEPADA LEMBAGA MA'HAD ABU UBAIDAH BIN AL-JARRAH MEDAN SUMATERA UTARA
}

\author{
BADRUL HELMI \\ Alumni Program Studi Komunikasi Islam Program Pascasarjana Universitas Islam \\ Negeri Sumatera Utara \\ Email: aljamahiriyah@yahoo.co.id
}

\begin{abstract}
Abstrak: Penelitian ini bertujuan untuk menjelaskan: Pertama, hubungan komunikasi antarpribadi pimpinan-bawahan dengan kesetiaan kepada lembaga Ma'had Abu Ubaidah bin Al-Jarrah Medan Sumatera Utara. Kedua, hubungan kepuasan kerja dengan kesetiaan kepada lembaga Ma'had Abu Ubaidah bin AlJarrah Medan Sumatera Utara. Ketiga, hubungan komunikasi antarpribadi pimpinan-bawahan dan kepuasan kerja dengan kesetiaan kepada lembaga Ma'had Abu Ubaidah bin Al-Jarrah Medan Sumatera Utara. Data penelitian ini dikumpulkan melalui teknik kuesioner dengan jumlah responden sebanyak 25 orang dosen Bahasa Arab dan pegawai yang ada di Ma'had Abu Ubaidah bin AlJarrah Medan Sumatera Utara. Untuk mendapatkan instrumen pengumpul data yang valid dan reliabel, maka diadakan uji coba validitas dan reliabilitas instrumen kepada 25 orang pegawai STAI As-Sunnah Deli Serdang Kecamatan Tanjung Morawa. Hasil uji coba validitas instrumen menunjukkan bahwa dari 123 item pertanyaan yang diajukan untuk ketiga variabel, ternyata tidak seluruhnya dinyatakan valid. Item yang valid digunakan sebagai data, sementara item yang tidak valid dibuang seluruhnya. Adapun hasil uji coba reliabilitas instrumen, semua data memiliki reliabilitas yang tinggi. Analisis data menggunakan metode kuantitatif dengan analisis korelasional. Pengolahan dan analisis data menggunakan bantuan software komputer SPSS 22. Hasil penelitian menunjukkan: Pertama, hubungan antara variabel komunikasi antarpribadi pimpinan-bawahan dengan variabel kesetiaan kepada lembaga Ma'had Abu Ubaidah bin Al-Jarrah Medan Sumatera Utara tertera angka 0.336**. Hubungan kedua variabel adalah positif dan signifikan. Kedua, hubungan antara variabel kepuasan kerja dengan variabel kesetiaan kepada lembaga Ma'had Abu Ubaidah bin Al-Jarrah Medan Sumatera Utara tertera angka 0.589**.Hubungan kedua variabel ini menunjukkan hasil yang positif dan signifikan. Ketiga, hubungan antara variabel komunikasi antarpribadi pimpinan-bawahan (variabel bebas) dan variabel kepuasan kerja (variabel bebas) dengan variabel kesetiaan kepada lembaga Ma'had Abu Ubaidah bin Al-Jarrah Medan Sumatera Utara (variabel terikat) menunjukkan angka korelasi sebesar 0.510**. Arah hubungan kedua variabel ini adalah positif dan signifikan.
\end{abstract}

Kata kunci : komunikasi antarpribadi, pimpinan-bawahan, kepuasan kerja, kesetiaan kepada lembaga 


\section{Pendahuluan}

Komunikasi merupakan keperluan asas bagi sebuah lembaga atau organisasi. Struktur, skop dan kemajuan lembaga pada keseluruhannya, ditentukan oleh teknik-teknik komunikasi. Karena itu, komunikasi sering dipandang sebagai intipati dalam kegiatan lembaga (Kholil:2006:161).

Seorang pimpinan sangat memerlukan informasi yang benar setiap kali dia membuat keputusan atau menyelesaikan konflik yang terjadi dalam lembaga. Bawahan juga memerlukan informasi yang dapat membantu mereka dalam menyelesaikan tugas-tugas yang diperintahkan. Semakin banyak informasi yang diketahui oleh pegawai, maka akan semakin baik pula mereka menyelesaikan tugas-tugas yang diembannya (Kholil:2006:161-162).

Suatu hal yang perlu diketahui oleh pimpinan adalah keadaan bawahan yang mempunyai sikap, perasaan, tingkah laku, kepribadian dan kemampuan yang berbeda-beda. Mereka juga memerlukan informasi yang bermacam-macam. Mereka ingin mengetahui tujuan lembaga, perencanaan dan program lembaga serta strategi untuk mencapainya. Mereka juga ingin mengetahui setiap masalah yang dialami oleh lembaga serta usaha yang ditempuh untuk mengatasinya.

Di samping itu, pegawai juga mempunyai masalah yang berhubungan dengan tugas ataupun luar tugas mereka. Mereka juga mempunyai uneg-uneg yang berkenaan dengan tugas, gaji dan peraturan lembaga dan perlu diketahui oleh pimpinan. Mereka memerlukan umpan balik atau penilaian tentang prestasi kerja mereka. Semua persoalan tersebut hanya dapat terungkap melalui komunikasi antarpribadi yang akrab antara pimpinan-bawahan, sehingga mereka merasa puas dalam melakukan pekerjaannya serta setia terhadap lembaga tempat mereka bekerja (Kholil:2006:162).

Ma'had Abu Ubaidah bin Al-Jarrah Medan Sumatera Utara sebagai salah satu lembaga pendidikan tinggi juga mengalami hal yang sama. Pimpinan Ma'had Abu Ubaidah bin Al-Jarrah Medan Sumatera Utara harus banyak berkomunikasi dengan para pegawainya, sehingga informasi penting yang menyangkut Ma'had Abu Ubaidah bin Al-Jarrah Medan Sumatera Utara dan terkait dengan 
pelaksanaan tugas-tugas pegawai, dapat mereka ketahui. Selama ini belum pernah diteliti bagaimana komunikasi antarpribadi pimpinan-bawahan di Ma'had Abu Ubaidah bin Al-Jarrah Medan Sumatera Utara, sudah berjalan lancar atau belum. Demikian juga belum pernah diteliti bagaimana tingkat kepuasan kerja para pegawai dan kesetiaan kepada Ma'had Abu Ubaidah bin Al-Jarrah Medan Sumatera Utara, serta hubungan komunikasi antarpribadi pimpinan-bawahan dan kepuasan kerja dengan kesetiaan kepada Ma'had Abu Ubaidah bin Al-Jarrah Medan Sumatera Utara. Padahal masalah ini amat perlu diteliti. Karena itu penulis merasa tertarik untuk meneliti masalah ini.

\section{Tujuan Penelitian}

1. Mengetahui hubungan komunikasi antarpribadi pimpinan-bawahan dengan kesetiaan kepada Lembaga Ma'had Abu Ubaidah bin Al-Jarrah Medan Sumatera Utara.

2. Mengetahui hubungan kepuasan kerja dengan kesetiaan kepada Lembaga Ma'had Abu Ubaidah bin Al-Jarrah Medan Sumatera Utara.

3. Mengetahui hubungan komunikasi antarpribadi pimpinan-bawahan dan kepuasan kerja dengan kesetiaan kepada Lembaga Ma'had Abu Ubaidah bin Al-Jarrah Medan Sumatera Utara.

\section{Kajian Pustaka}

\section{Teori Hubungan Manusiawi}

Landasan teori yang digunakan dalam penelitian ini adalah human relations theory (teori hubungan manusiawi) yang bersumber dari Elton Mayo (1880-1949). Mayo menekankan urgensi aspek hubungan manusia atau hubungan antarpribadi dalam lembaga atau organisasi. Menurut Mayo, pada prinsipnya manusia senantiasa patuh, taat, suka diajari, tidak suka mengkritik dan membutuhkan pimpinan. Manusia berkeinginan untuk bersatu dan berkeinginan agar hidupnya lebih bermanfaat. Mayo menolak teori tradisional yang berpendapat bahwa tujuan utama seseorang untuk bekerja adalah demi memperoleh uang guna memenuhi kebutuhan hidupnya (Kholil:2006:172-173). 
Mayo menyatakan bahwa hubungan kelompok secara informal lebih penting dan lebih kuat daripada kondisi kerja dalam menentukan moral dan produktivitas (Pace dan Faules:2010:70).

Teori hubungan manusiawi ini muncul pada tahun 1930-an yang merupakan hasil dari studi Hawthorne. Inti dari hasil studi ini adalah bahwa seorang pekerja bukanlah sekedar alat yang sederhana, tapi suatu kepribadian yang kompleks dan selalu berinteraksi dengan kelompoknya di lingkungan kerja. Problem kemanusiaan tidaklah boleh dibiarkan berlalu begitu saja, tetapi harus dicari solusinya melalui berbagai studi yang bisa menciptakan studi baru yang khusus menangani hal ini (Harbi:2003:10).

Menurut Mayo melalui studi Hawthorne di atas, terdapat motif pada diri pekerja (selain motif materi) yang sangat berpengaruh terhadap hasil produksi. Motif ini dikenal dengan motif sosial, yaitu bahwa pekerja itu juga manusia yang merupakan makhluk sosial dan selalu beradaptasi dan berinteraksi dengan anggota kelompoknya di tempat dia bekerja (Syuhainaz:2012:24).

Dua kesimpulan yang berkembang dari studi Hawthorne di atas sering disebut efek Hawthorne atau The Hawthorne Effect, yaitu:

1. Perhatian terhadap orang-orang mungkin bisa mengubah sikap dan perilaku mereka.

2. Moral dan produktivitas dapat meningkat apabila para pegawai mempunyai kesempatan untuk berinteraksi satu sama lain (Pace dan Faules:2010:60).

Salah seorang ahli teori organisasi yang berusaha memantapkan pandangan Mayo tadi ialah Barnard (1938). Dia merupakan ahli teori organisasi yang pertama mengatakan bahwa organisasi merupakan suatu sistem kerjasama. Sikap bekerjasama antara pimpinan dan bawahan mesti lahir secara spontan dan bukan didorong oleh motif keuntungan. Barnard juga menegaskan bahwa konflik harus dikurangi supaya suasana kerjasama itu dapat hidup dan berkembang. Sikap kerjasama ini lahir karena hasrat bersama untuk mencapai tujuan organisasi yang akan memberikan keuntungan bagi kedua belah pihak (Kholil:2006:174). 
Seorang bawahan boleh jadi mau menerima suatu pesan dengan penuh kehangatan dan penerimaan, bawahan lainnya tidak mau menerima tetapi juga tidak berarti menolaknya, sedangkan seorang bawahan ketiga sama sekali menolak pesan tersebut (Pace dan Faules:2010:57-58).

Suatu contoh penolakan penerimaan kewenangan total terjadi pada masa perang Rusia-Jepang (1904-1905). Kapal laut Rusia, Potemkin, menurut suatu laporan, sedang melakukan suatu manuver di Laut Hitam. Sakit hati para pelaut terhadap atasan mereka yang tadinya biasa saja menjadi berlipat ganda dengan adanya kebijakan disiplin yang keras. Mengetahui bahwa perang Rusia-Jepang dikelola secara buruk, para penghasut berusaha menimbulkan suatu pemberontakan pada Potemkin, namun tidak begitu berhasil. Namun, pada suatu hari para pegawai kapal melihat daging yang telah berbelatung tergantung di dapur kapal. Untuk meyakinkan bahwa daging tersebut dapat dimakan, dokter kapal dipanggil. Pada suatu jamuan makan malam, awak kapal diberi sup yang mengandung daging yang telah membusuk itu. Sebagai aksi pemberontakan, awak kapal hanya menyantap roti dan air, membiarkan sup yang tidak terjamah itu. Hal ini membuat kapten kapal marah dan memaksa awak kapal agar memakan sup tersebut. Karena usahanya gagal, seorang atasan lainnya turun tangan dalam situasi yang menegangkan itu, memanggil pengawal bersenjata dan memerintahkan semua pelaut agar mau makan. Dari ratusan orang, hanya 30 orang saja yang mematuhi perintahnya. Sang pemimpin memerintahkan awak kapal yang keras kepala agar ditutup dengan kain terpal sebagai persiapan untuk mendapatkan hukuman tembak. Ketika para pelaut itu berdempetan dengan ditutup kain terpal itu, atasan memberi perintah menembak. Para pengawal bersenjata ragu-ragu. Pada saat itu, para pelaut lainnya buru-buru mendesak para pengawal bersenjata agar mengarahkan moncong-moncong senjata mereka ke atasan-atasan tersebut yang tadinya diarahkan ke kawan-kawan mereka. Sementara perwira senior itu meneriakkan perintah dan atasan-atasan lainnya berdiri dengan kaget, para pengawal bersenjata menembaki mereka. Kebanyakan atasan, termasuk kapten kapal tertembak dan dilemparkan ke laut. Jadi, 
kewenangan formal sama sekali tidak efektif karena ditolak oleh awak kapal dan para pengawal bersenjata (Pace dan Faules:2010:58).

Seperti teori-teori lain, teori hubungan manusiawi tidak terlepas dari kelemahan-kelemahan. Kelemahan-kelemahan itu antara lain bahwa teori ini dipandang terlalu simplistik karena mengkaitkan hubungan yang tinggi antara moral dan produksi. Korelasi antara faktor kemanusiaan dan keberkesanan tidak ditemui apabila diadakan pengujian secara empiris. Korelasi tersebut dalam banyak kasus tidak ditemui, dan seandainya ditemukan terdapat hubungan di antara keduanya, maka peneliti tersebut akan dihujani dengan berbagai pertanyaan tentang metodologi penelitian yang digunakan (Kholil:2006:185).

Teori ini terlalu fokus kepada faktor psikologi, sosial, komunikasi informal, dan mewujudkan suasana kekeluargaan di lingkungan kerja (Syannah:2007:53).

Kelemahan yang paling menonjol adalah bahwa teori ini mengabaikan variabel yang bukan manusia. Teori ini mengabaikan faktor ekonomi yang sebenarnya ikut berperan dalam menentukan tingkat produksi. Dengan perkataan lain, teori ini tidak memperhitungkan saling hubungan antara berbagai unsur struktural dan fungsional dengan produksi organisasi (Kholil:2006:185).

Walaupun teori hubungan manusiawi dipandang agak ekstrim dan dipandang dapat memanipulasikan para pekerjanya, namun tidak dapat dinafikan bahwa teori ini telah banyak membantu para ahli untuk memahami bahwa setiap manusia mempunyai keperluan dan nilai-nilai yang berkaitan dengan fungsi organisasi. Teori ini juga memberi kesadaran kepada manusia tentang betapa pentingnya komunikasi dalam organisasi (Kholil:2006:186).

Teori hubungan manusiawi ini juga mempunyai nilai huristik, karena berpotensi untuk menambah penelitian baru. Hal ini dapat dibuktikan dengan lahirnya pendekatan sumber manusia tadi. Teori ini juga sekurang-kurangnya berguna untuk menyadarkan pimpinan supaya tidak terlalu mementingkan masalah produksi, dan mengabaikan nilai-nilai kemanusiaan yang cenderung menganggap manusia sebagai robot atau mesin (Kholil:2006:187). 
Dengan demikian, walaupun teori ini memiliki berbagai kekurangan, namun masih tetap penting dalam suatu lembaga dan sekaligus turut memberikan sumbangan penting dalam teori komunikasi kemanusiaan.

\section{Kerangka Konsep}

Ada tiga konsep penting dalam penelitian ini, yaitu komunikasi antarpribadi pimpinan-bawahan, kepuasan kerja dan kesetiaan kepada lembaga. Pengertian ketiga konsep ini adalah sebagai berikut:

1. Komunikasi Antarpribadi Pimpinan-bawahan

Komunikasi antarpribadi pimpinan-bawahan diartikan sebagai proses pertukaran informasi antara pimpinan dan bawahan. Pimpinan dalam penelitian ini ialah orang yang menduduki posisi lebih tinggi dalam hirarki lembaga, yaitu direktur. Bawahan adalah dosen Bahasa Arab dan pegawai administrasi. Karena mereka inilah yang dipandang mempunyai pimpinan (atasan) di lingkungan Ma'had Abu Ubaidah bin Al-Jarrah Medan Sumatera Utara. Sub variabel yang digunakan untuk variabel ini ialah:
a. Komunikasi membina.
b. Komunikasi terbuka.
c. Peluang komunikasi ke atas (bottom up).
d. Mutu informasi ke bawah (top down).

2. Kepuasan Kerja

Holley dan Jennings (1983) mengartikan kepuasan kerja sebagai penilaian seseorang terhadap kerjanya dari segi bimbingan yang diberikan, gaji, pangkat dan pekerjaan itu sendiri. Kepuasan kerja dalam penelitian ini meliputi:

a. Kepuasan yang bersifat internal, yaitu kepuasan yang diperoleh melalui pekerjaan itu sendiri.

b. Kepuasan yang bersifat eksternal, yaitu kepuasan yang diperoleh dari luar tetapi terkait dengan pekerjaan.

3. Kesetiaan kepada Lembaga 
Kesetiaan kepada lembaga dalam penelitian ini ialah:

a. Keinginan pegawai untuk bekerja tanpa harus diamati pimpinan.

b. Perasaan sayang dan memiliki Ma'had Abu Ubaidah bin Al-Jarrah Medan Sumatera Utara.

Komunikasi antarpribadi pimpinan-bawahan yang meliputi komunikasi membina, komunikasi terbuka, peluang komunikasi ke atas, dan mutu informasi ke bawah; dan kepuasan kerja yang meliputi kepuasan yang bersifat internal dan kepuasan yang bersifat eksternal, dipandang dapat mempengaruhi kesetiaan kepada lembaga Ma'had Abu Ubaidah bin Al-Jarrah Medan Sumatera Utara yang meliputi keinginan pegawai untuk bekerja tanpa harus diamati pimpinan dan perasaan sayang dan memiliki Ma'had Abu Ubaidah bin Al-Jarrah Medan Sumatera Utara.

\section{Pengajuan Hipotesis}

Ada tiga hipotesis yang diuji dalam penelitian ini, yaitu:

1. Terdapat hubungan yang positif dan signifikan komunikasi antarpribadi pimpinan-bawahan dengan kesetiaan dosen Bahasa Arab dan pegawai kepada lembaga Ma'had Abu Ubaidah bin Al-Jarrah Medan Sumatera Utara.

2. Terdapat hubungan yang positif dan signifikan kepuasan kerja dengan kesetiaan dosen Bahasa Arab dan pegawai kepada lembaga Ma'had Abu Ubaidah bin Al-Jarrah Medan Sumatera Utara.

3. Terdapat hubungan yang positif dan signifikan komunikasi antarpribadi pimpinan-bawahan dan kepuasan kerja dengan kesetiaan dosen Bahasa Arab dan pegawai kepada lembaga Ma'had Abu Ubaidah bin Al-Jarrah Medan Sumatera Utara.

\section{Metodologi Penelitian}

Pendekatan yang digunakan dalam penelitian ini ialah pendekatan komunikasi yang berlandaskan teori hubungan manusiawi yang bersumber dari Mayo. Penelitian ini tergolong kepada penelitian kuantitatif yang bersifat 
korelasional, yaitu melibatkan tindakan pengumpulan data guna menentukan, apakah ada hubungan dan tingkat hubungan antara dua variabel atau lebih.

Lokasi penelitian adalah Ma'had Abu Ubaidah bin Al-Jarrah, Jl. Dr. Mansyur, Gg. Berdikari / Jl. Sukabaru, No. 17 E, Kec. Medan Selayang, Medan, Sumatera Utara. Telp. 061-8226157. Email: abuubaidah@mdn.centrin.net.id / abu_ubaidah8@yahoo.com.

Populasi penelitian ini adalah keseluruhan dosen Bahasa Arab Ma'had Abu Ubaidah bin Al-Jarrah Medan Sumatera Utara dengan posisi Direktur ke bawah yang mempunyai masa kerja minimal tiga bulan, dan pegawai administrasi setingkat Kepala Administrasi ke bawah yang juga telah bekerja di Ma'had Abu Ubaidah bin Al-Jarrah Medan Sumatera Utara minimal tiga bulan. Populasi penelitian ini dari kalangan dosen Bahasa Arab berjumlah 16 orang, dan dari kalangan administrasi 10 orang. Total populasi adalah 26 orang.

Kartini Kartono menyarankan agar mengambil seluruh anggota populasi apabila jumlah populasi hanya di antara 10 - 100 orang/satuan. Oleh karena itu, teknik pengambilan sampel ini adalah diambil semua jumlah populasi (total sampling saja setelah dikeluarkan unsur pimpinan) sehingga penelitiannya merupakan penelitian populasi.

Jumlah populasi penelitian ini adalah 26 orang, dikurangi unsur pimpinan 1 orang, menjadi 25 orang. Jadi, sampel penelitian ini ditetapkan 25 orang, dengan perincian 15 orang dari kalangan dosen Bahasa Arab dan 10 orang dari kalangan pegawai administrasi.

Operasional variabel penelitian adalah penelitian yang terkait dengan pengukuran variabel yang terdapat dalam judul penelitian sesuai dengan hasil perumusan masalah. Dalam penelitian ini, pengukuran variabel menggunakan skala Likert.

Ada tiga variabel utama dalam penelitian ini, yaitu (1) komunikasi antarpribadi pimpinan-bawahan, (2) kepuasan kerja, dan (3) kesetiaan kepada lembaga Ma'had Abu Ubaidah bin Al-Jarrah Medan Sumatera Utara. Ketiga variabel ini diukur dengan menggunakan kuesioner yang dimodifikasi dari Dennis (1974), kemudian dari Warr, Cook \& Wall (1979), dengan kisi-kisi instrumen 
sebagai berikut: (1) komunikasi antarpribadi pimpinan-bawahan (variabel bebas) yang terdiri dari (a) komunikasi membina (item 1-25), (b) komunikasi terbuka (item 26-38), (c) peluang komunikasi ke atas ((item 39-75), dan (d) mutu informasi ke bawah (item 76-81); (2) kepuasan kerja (variabel bebas) yang terdiri dari (a) kepuasan yang bersifat internal (item 82-98), dan (b) kepuasan yang bersifat eksternal (item 99-114); dan (3) kesetiaan kepada lembaga Ma'had Abu Ubaidah bin Al-Jarrah Medan Sumatera Utara (variabel terikat) yang terdiri dari (a) keinginan pegawai untuk bekerja tanpa harus diamati pimpinan (item 115117), dan (b) perasaan sayang dan memiliki Ma'had Abu Ubaidah bin Al-Jarrah Medan Sumatera Utara (item 118-123).

Data dianalisis dengan menggunakan korelasi product moment yang bersumber dari Karl Pearson dengan menggunakan Statistical Product and Service Solution (SPSS) for Windows Versi 22. Data dianalisis dengan statistik deskriptif dan inferensial.

\section{Hasil Penelitian dan Pembahasan}

Hubungan Komunikasi Antarpribadi Pimpinan-bawahan dengan Kesetiaan kepada Lembaga Ma'had Abu Ubaidah bin Al-Jarrah Medan Sumatera Utara

Berdasarkan hasil penelitian, dinyatakan bahwa ada pengaruh komunikasi antarpribadi pimpinan-bawahan terhadap kesetiaan kepada Lembaga Ma'had Abu Ubaidah bin Al-Jarrah Medan Sumatera Utara, tetapi pengaruh tersebut rendah, karena nilai koefisien korelasi yang didapat adalah sebesar $0.336^{* *}$, sedangkan koefisien korelasi $\mathrm{r}=0.336^{* *}$ berada di antara 0.200-0.400.

Walaupun terdapat pengaruh yang rendah antara komunikasi antarpribadi pimpinan-bawahan dengan kesetiaan kepada lembaga Ma'had Abu Ubaidah bin Al-Jarrah Medan Sumatera Utara, diharapkan lembaga dapat lebih meningkatkan peran komunikasi antarpribadi pimpinan-bawahan terhadap kesetiaan kepada lembaga Ma'had Abu Ubaidah bin Al-Jarrah Medan Sumtera Utara, karena dengan lebih memperhatikan dan meningkatkan frekuensi komunikasi antarpribadi pimpinan-bawahan kedepannya diharapkan dapat menumbuhkan 
sikap loyal yang tinggi dari dosen Bahasa Arab dan pegawai terhadap Ma'had Abu Ubaidah bin Al-Jarrah Medan Sumatera Utara.

Oleh karena itu, perlu dibina hubungan yang lebih baik lagi antara pimpinan dan bawahan dengan perhatian penuh terhadap komunikasi antarpribadi dan kepemimpinan yang baik.

Pimpinan yang baik berupaya melakukan pendekatan kepada bawahan secara bertahap sehingga tercipta hubungan yang akrab antara pimpinan dan bawahan. Hal ini hendaknya dipertahankan agar suasana kerja tetap nyaman.

Pimpinan yang baik berupaya menciptakan hubungan dengan bawahan yang saling menguntungkan sehingga hubungan yang erat tetap bisa dipertahankan.

Pimpinan yang baik berupaya menciptakan saling ketergantungan dalam lembaga. Dengan adanya saling ketergantungan ini, potensi konflik bisa dikurangi.

Setiap individu dalam lembaga hendaknya bertindak sesuai dengan ekspedisi peranan (role expectation) dan tuntutan peranan (role demands), memiliki keterampilan peranan (role skills), dan terhindar dari konflik peranan dan kerancuan peranan. Dengan demikian, pimpinan dan bawahan harus bisa memainkan peranan masing-masing, sehingga tidak ada yang merasa peranannya diserobot.

Selanjutnya setelah dilakukan uji signifikansi, ternyata antara variabel komunikasi antarpribadi pimpinan-bawahan (X1) dengan variabel kesetiaan kepada Lembaga Ma'had Abu Ubaidah bin Al-Jarrah Medan Sumatera Utara (Y) memiliki hubungan yang positif dan signifikan. Hal ini dikarenakan nilai signifikansi setelah dilakukan proses perhitungan dengan SPSS 22 diperoleh hasil sebesar 0.01. Karena nilai signifikansi $0.01<0.05$ maka Ho ditolak. Jadi, dapat disimpulkan bahwa ada hubungan yang positif dan signifikan komunikasi antarpribadi pimpinan-bawahan dengan kesetiaan kepada Lembaga Ma'had Abu Ubaidah bin Al-Jarrah Medan Sumatera Utara.

Dengan demikian dapat disimpulkan bahwa antara komunikasi antarpribadi pimpinan-bawahan dengan kesetiaan kepada Lembaga Ma'had Abu 
Ubaidah bin Al-Jarrah Medan Sumatera Utara memiliki pengaruh yang rendah dan hubungan yang positif dan signifikan.

\section{Hubungan Kepuasan Kerja dengan Kesetiaan kepada Lembaga Ma'had Abu Ubaidah bin Al-Jarrah Medan Sumatera Utara}

Antara variabel kepuasan kerja (X2) dengan kesetiaan kepada Lembaga Ma'had Abu Ubaidah bin Al-Jarrah Medan Sumatera Utara (Y). Dari tabel output analisis antara varibabel kepuasan kerja dan kesetiaan kepada Lembaga Ma'had Abu Ubaidah bin Al-Jarrah Medan Sumatera Utara dapat dijelaskan bahwa terdapat pengaruh yang sedang atau cukup dengan kesetiaan kepada Lembaga Ma'had Abu Ubaidah bin Al-Jarrah Medan Sumatera Utara, karena nilai koefisien korelasi yang didapat adalah sebesar $0.589^{* *}$, sedangkan koefisien korelasi $\mathrm{r}=$ $0.589 * *$ berada di antara 0.400-0.600.

Dengan munculnya sikap puas dalam diri dosen Bahasa Arab dan pegawai Ma'had Abu Ubaidah bin Al-Jarrah Medan Sumatera Utara, diharapkan lebih meningkatkan sifat setia atau loyal kepada lembaga Ma'had Abu Ubaidah bin AlJarrah Medan Sumatera Utara. Dari hasil penelitian ini, ternyata penerapan disiplin yang tinggi, gaji dosen Bahasa Arab dan pegawai, penghargaan terhadap dosen Bahasa Arab dan pegawai, ataupun kepuasan lainnya yang bersifat internal dari lembaga dapat mempengaruhi sikap setia dan loyal kepada lembaga Ma'had Abu Ubaidah bin Al-Jarrah Medan Sumatera Utara.

Selain itu, kepuasan yang bersifat eksternal seperti peluang karir ke depan, lingkungan yang menyenangkan, rekan kerja, sarana dan prasarana kerja, manajemen lembaga ataupun kepuasan dosen Bahasa Arab dan pegawai lainnya yang bersifat eksternal dapat meningkatkan sikap setia dan loyal kepada lembaga Ma'had Abu Ubaidah bin Al-Jarrah Medan Sumatera Utara.

Selanjutnya antara variabel kepuasan kerja (X2) dengan variabel kesetiaan kepada Lembaga Ma'had Abu Ubaidah bin Al-Jarrah Medan Sumatera Utara (Y) menunjukkan adanya hubungan yang positif dan signifikan. Dikatakan signifikan karena nilai signifikansi analisis antara kepuasan kerja dengan kesetiaan kepada Lembaga Ma'had Abu Ubaidah bin Al-Jarrah Medan Sumatera Utara sebesar 0.01. Karena nilai signifikansi $0.01<0.05$ maka Ho ditolak. Jadi, dapat 
disimpulkan bahwa antara variabel kepuasan kerja (X2) dengan variabel kesetiaan kepada Lembaga Ma'had Abu Ubaidah bin Al-Jarrah Medan Sumatera Utara (Y) terdapat hubungan yang positif dan signifikan.

Oleh karena itu, supaya kesetiaan dosen Bahasa Arab dan pegawai kepada Ma'had Abu Ubaidah bin Al-Jarrah Medan Sumatera Utara dapat terealisasikan dengan lebih baik lagi maka diharapkan kepada pimpinan lembaga tersebut agar lebih meningkatkan lagi aspek-aspek yang berkatian dengan kepuasan kerja dosen Bahasa Arab dan pegawai Ma'had Abu Ubaidah bin Al-Jarrah Medan Sumatera Utara, seperti memberikan perhatian terhadap lingkungan kerja yang menyenangkan, bersih, rapi, memenuhi standar kesehatan, penerangan yang cukup, gaji yang standar, dan lain-lain.

Dengan demikian dapat disimpulkan bahwa antara kepuasan kerja dengan kesetiaan kepada lembaga Ma'had Abu Ubaidah bin Al-Jarrah Medan Sumatera Utara terdapat pengaruh yang sedang atau cukup dan hubungan yang positif dan signifikan.

\section{Hubungan Komunikasi Antarpribadi Pimpinan-bawahan dan Kepuasan} Kerja dengan Kesetiaan kepada Lembaga Ma'had Abu Ubaidah bin AlJarrah Medan Sumatera Utara

Selanjutnya dari hasil pengujian hipotesis antara variabel komunikasi antarpribadi pimpinan-bawahan dan kepuasan kerja (variabel bebas) dengan kesetiaan kepada Lembaga Ma'had Abu Ubaidah bin Al-Jarrah Medan Sumatera Utara (variabel terikat) diketahui bahwa koefisien korelasi $\mathrm{r}=0.510^{* *}$. Oleh karena itu, dinyatakan bahwa ada pengaruh yang sedang atau cukup antara variabel bebas (komunikasi antarpribadi pimpinan-bawahan dan kepuasan kerja) dan variabel terikat (kesetiaan kepada Lembaga Ma'had Abu Ubaidah bin AlJarrah Medan Sumatera Utara) karena koefisien korelasi $\mathrm{r}=0.510 * *$ berada di antara 0.400- 0.600 .

Selanjutnya antara variabel bebas (komunikasi antarpribadi pimpinanbawahan dan kepuasan kerja) dan variabel terikat (kesetiaan kepada Lembaga Ma'had Abu Ubaidah bin Al-Jarrah Medan Sumatera Utara) terdapat hubungan 
yang signifikan. Dinyatakan signifikan karena nilai signifikansi $0.01<0.05$. Oleh karena itu, Ho ditolak. Berdasarkan pernyataan tersebut berarti antara variabel bebas (komunikasai antarpribadi pimpinan-bawahan dan kepuasan kerja) dengan variabel terikat (kesetiaan kepada Lembaga Ma'had Abu Ubaidah bin Al-Jarrah Medan Sumatera Utara) terdapat hubungan yang positif signifikan.

Jadi, dapat disimpulkan bahwa antara komunikasi antarpribadi pimpinanbawahan (X1) dan kepuasan kerja (X2) dengan kesetiaan kepada Lembaga Ma'had Abu Ubaidah bin Al-Jarrah Medan Sumatera Utara (Y) terdapat hubungan yang positif dan signifikan. Dengan demikian diharapkan kepada setiap pimpinan sebuah lembaga supaya lebih memahami konsep komunikasi antarpribadi pimpinan-bawahan dan kepuasan kerja agar kesetiaan kepada suatu lembaga dapat tercipta sesuai dengan yang diharapkan.

\section{Penutup}

Dari hasil penelitian di atas dapat disimpulkan bahwa hubungan antara variabel komunikasi antarpribadi pimpinan-bawahan dengan kesetiaan kepada Lembaga Ma'had Abu Ubaidah bin Al-Jarrah Medan Sumatera Utara adalah positif dan signifikan. Adapun pengaruh antara kedua variabel adalah rendah (lemah). Angka koefisien korelasinya adalah sebesar 0.336**.

Demikian juga hubungan antara variabel kepuasan kerja dengan kesetiaan kepada Lembaga Ma'had Abu Ubaidah bin Al-Jarrah Medan Sumatera Utara adalah positif dan signifikan. Pengaruh antara kedua variabel adalah sedang atau cukup. Angka koefisien korelasinya adalah sebesar $0.589 * *$.

Hubungan antara kedua variabel bebas (komunikasi antarpribadi pimpinan-bawahan dan kepuasan kerja) dengan variabel terikat (kesetiaan kepada Lembaga Ma'had Abu Ubaidah bin Al-Jarrah Medan Sumatera Utara) menunjukkan angka koefisien korelasi sebesar 0.510**. Hal ini berarti secara bersama-sama kedua variabel bebas (komunikasi antarpribadi pimpinan-bawahan) memiliki pengaruh yang sedang atau cukup dengan variabel terikat (kesetiaan kepada Lembaga Ma'had Abu Ubaidah bin Al-Jarrah Medan Sumatera Utara). Arah hubungan antara dua variabel adalah positif dan signifikan. 


\section{PUSTAKA Acuan}

Harbi, al, Khalid ibn Hamdi al-Humaidi. "Aṡar al-'Alaqat al-Insaniyyah 'ala Ada' al-'Amilin fi al-Ajhizah al-Amniyyah: Dirasah 'ala al-'Amilin bi Idarah Jawazat Mantiqah ar-Riyad wa al-Mantiqah asy-Syarqiyyah”. Tesis, Program Pascasarjana Jami'ah Nayif al-'Arabiyyah li al-'Ulum alAmniyyah Riyad, 2003.

Hartono. Statistik untuk Penelitian. Yogyakarta: Pustaka Pelajar, cet. 6, 2012.

Kholil, Syukur. Metodologi Penelitian Komunikasi. Bandung: Cita Pustaka Media, cetakan pertama, 2006.

Mayo, Elton. The Social Problems of an Industrial Civilization. Androver, Massachusetts: Androver Press, 1945.

Munandar, Ashar Sunyoto. Psikologi Industri dan Organisasi. Jakarta: Universitas Indonesia Press, 2014.

Noor, Juliansyah. Metodologi Penelitian: Skripsi, Tesis, Disertasi dan Karya Ilmiah. Jakarta: Kencana Prenada Media Group, cet. 4, 2014.

Pace, R. Wayne dan Don F. Faules. Organizational Communication, terj. Deddy Mulyana et. al., Komunikasi Organisasi: Strategi Meningkatkan Kinerja Perusahaan. Bandung: Remaja Rosdakarya, cet. 7, 2010.

Priyatno, Duwi. SPSS 22: Pengolah Data Terpraktis. Yogyakarta: Andi, 2014.

Romli, Khomsahrial. Komunikasi Organisasi Lengkap. Jakarta: Gramedia, edisi revisi, 2014.

Soewadji, Jusuf. Pengantar Metodologi Penelitian. Jakarta: Mitra Wacana Media, edisi asli, 2012.

Syahrum dan Salim. Metodologi Penelitian Kuantitatif. Bandung: Cita Pustaka Media, 2009.

Syannah, Muhammad Rida. "Istratijiyyah Idarah as-Sira" at-Tanzimi bi alMu'assasah as-Sina'iyyah al-Jaza'iriyyah: Dirasah Maidaniyyah 'ala 'Ayyinah min al-Mu'assasat bi asy-Syarq al-Jaza'iri Halat Qisintinah Sutaif - Baskarah". Tesis, Program Pascasarjana Jami'ah Manturi Qisintinah, 2007.

Syuhainaz, Dariyusy. "Aar Anmat al-Qiyadah al-Idariyyah 'ala Tanmiyah Ibda" al-Mawarid al-Basyariyyah: Dirasah Maidaniyyah li 'Ayyinah min alMu'assasat as-Sina'iyyah al-Khassah bi Wilayah Qisintinah”. Tesis, Program Pascasarjana Jami'ah Manturi Qisintinah, 2012. 